\title{
Effects of ornithine $\alpha$-ketoglutarate on insulin secretion in rat pancreatic islets: implication of nitric oxide synthase and glutamine synthetase pathways*
}

\author{
Christina Schneid ${ }^{1,2}$, Sylviane Darquy ${ }^{1,2}$, Luc Cynober ${ }^{1,2}$, Gérard Reach ${ }^{1}$ and Jean-Pascal De Bandt ${ }^{1,2} \dagger$ \\ ${ }^{1}$ INSERM U-341, Service de Diabètologie, Hôpital Hôtel-Dieu, Paris, France \\ ${ }^{2}$ Laboratoire de Biologie de la Nutrition EA 2498, Faculté de Pharmacie-Paris 5, Paris, France
}

(Received 5 November 2001 - Revised 1 July 2002 - Accepted 5 September 2002)

\begin{abstract}
Ornithine $\alpha$-ketoglutarate (OKG) administration in human subjects elicits insulin secretion. We investigated whether this action was related to an effect of OKG on islets of Langerhans, and addressed the underlying mechanisms of action. For this purpose the influence of OKG on insulin secretion was measured in isolated rat islets of Langerhans under two different conditions. In incubated islets, OKG $(0.25$ to $2.5 \mathrm{mmol} / \mathrm{l})$ significantly and dose-relatedly increased insulin secretion (1.7- to 4.2-fold; $P<0.05 v$. basal). To study the kinetics of OKG-stimulated insulin secretion, perifusion experiments were performed, which showed that OKG affected insulin secretion in both initial and later phases. Experiments using $\alpha$-ketoglutarate $(\alpha-K G)$ $(1 \mathrm{mmol} / \mathrm{l})$ or ornithine (Orn) $(2 \mathrm{mmol} / \mathrm{l})$ alone, in concentrations equal to that of OKG, showed that the OKG-induced insulin secretion could not be obtained by either component alone, suggesting that an $\alpha-\mathrm{KG}-$ Orn interaction is mandatory for the insulin-secreting effect to occur. Since data obtained in vivo suggest that effects of OKG may depend on the synthesis of NO, glutamine and/or polyamines, three metabolic pathways potentially involved in insulin secretion, we then evaluated their contribution by means of their respective inhibitors: $\mathrm{L}_{-} \mathrm{N}^{\mathrm{G}}$ nitroarginine methyl ester (L-NAME), methionine sulfoximine (MSO) and difluoromethylornithine (DFMO). Both L-NAME and MSO were able significantly to reduce OKG-induced insulin secretion (30 and $40 \%$ respectively; $P<0.05$ ), while DFMO was ineffective. Thus $\mathrm{OKG}$ is an effective stimulator of insulin secretion, requiring the joint presence of both Orn and $\alpha-K G$, and acting mainly via the synthesis of NO and glutamine. A better understanding of OKG insulino-secretory properties and its mechanisms of action are a prerequisite for its use in insulin-compromised situations.
\end{abstract}

Nitric oxide: Polyamines: Glutamine

Ornithine $\alpha$-ketoglutarate $(\mathrm{OKG})$ is a salt composed of an $\alpha$-ketoglutarate $(\alpha-K G)$ moiety and two ornithine (Orn) moieties, which dissociates completely in solution (Cynober, 1995). Its anabolic and anti-catabolic properties were highlighted in the early 1960s with the observation of an improvement in the nutritional status of patients with liver failure receiving OKG (see Gay et al. 1979), prompting various studies to evaluate the benefit of $\mathrm{OKG}$ supplementation of enteral and parenteral nutrition. OKG has been demonstrated to improve $\mathrm{N}$ balance in surgical (Leander et al. 1985), burns (Cynober et al. 1984a, 1986), septic and polytrauma patients (Cynober, 1995), by either increasing protein synthesis or reducing protein breakdown (Cynober, 1995).

\footnotetext{
Abbreviations: Arg, arginine; DFMO, difluoromethylornithine; Glc, glucose; Gln, glutamine; $\alpha$-KG, $\alpha$-ketoglutarate; KRB, Krebs-Ringer buffer; LNAME, L-nitroarginine methyl ester; MSO, methionine sulfoximine; OKG, ornithine $\alpha$-ketoglutarate; Orn, ornithine.

*Parts of this work have been published in abstract form: Schneid C, Darquy S, Reach G, Cynober L \& De Bandt JP (2000) In vitro insulin stimulation in pancreatic islets by ornithine- $\alpha$-ketoglutarate. Diabetologia 43, Suppl. 1, A134; Schneid C, Darquy S, Reach G, Cynober L \& De Bandt JP (2000) $\alpha$-Cétoglutarate d'ornithine et sécrétion d'insuline par les îlots de Langerhans: Rôle de l'ornithine et de l' $\alpha$-cétoglutarate. Nutrition Clinique et Métabolisme 14, Suppl. 2, S131; Schneid C, Darquy S, Reach G, Cynober L \& De Bandt JP (2000) Etude des mécanismes impliqués dans la sécrétion d'insuline induite par l' $\alpha$-cétoglutarate d'ornithine dans un modèle d'îlots de Langerhans de rat. Diabetes \& Metabolism 27, Suppl. 1, $1 \mathrm{~S} 61$.

$†$ Corresponding author: Dr J.-P. De Bandt, fax +33 1423486 12, email jp.debandt@htd.ap-hop-paris.fr
} 
The effects of OKG may depend not only on the production of glutamine (Gln) and arginine (Arg), two amino acids that play important roles in protein anabolism and immune defence (Cynober, 1995; Le Boucher et al. 1999), but also on the production of other Orn metabolites such as polyamines. In addition, it has been argued that endocrine processes may be involved, with possible interactions between OKG and insulin secretion and/or peripheral action (Cynober, 1995). OKG may modulate the peripheral response to insulin action, as suggested by OKG-induced improvement in glucose tolerance in hyperinsulinaemic burn patients in the absence of any increase in insulinaemia (Vaubourdolle et al. 1987). However, an OKG-induced increase in insulinaemia has been demonstrated after both intravenous and oral OKG administration in healthy subjects (Krassowski et al. 1981; Cynober et al. 1990). An intriguing feature is that the action of OKG on insulinaemia (Cynober et al. 1990) could not be reproduced by administering either $\alpha-K G$ or Orn alone, suggesting that interactions between the two components of OKG are required to induce this effect. Such an interaction, related to the common metabolic pathway shared by Orn and $\alpha-K G$, has been demonstrated to be essential for some of the anabolic and anti-catabolic effects of OKG and the synthesis of Gln (Cynober, 1995; Le Boucher et al. 1997).

In addition, it has been demonstrated that both Orn and $\alpha-\mathrm{KG}$ may play a role in insulin secretion (Lenzen et al. 1986; Malaisse et al. 1989b). Malaisse et al. (1989a) have demonstrated in the pancreatic $\beta$-cell line RINm5F that Orn, like Arg, can stimulate insulin secretion by mechanisms independent of its conversion into Arg. Moreover, in both intact islets and islet homogenates, Orn is extensively metabolised in rat pancreatic islets (Malaisse et al. $1989 \mathrm{~b}$ ), suggesting that two metabolic pathways may be involved in the induction of insulin secretion, namely the generation of putrescine and other polyamines, and the conversion of Orn into L-glutamate (Malaisse et al. $1989 a$ ). On the other hand, studying mitochondrial homogenates of mice islets, Lenzen et al. (1986) have postulated a parallel between the generation of $\alpha-K G$ and the stimulation of insulin secretion by amino acids such as leucine.

However, data from the literature concerning OKG action on insulin secretion are only descriptive, with no information on the underlying mechanisms. The aim of the present study was thus to evaluate the effects of OKG at concentrations similar to those observed during in vivo $\mathrm{OKG}$ administration, and the contribution of Orn and $\alpha-K G$, its two components, on insulin secretion, and to investigate the metabolic pathways potentially involved in this action. For this purpose, rat islets of Langerhans were used under two experimental conditions: the static model of incubated islets; the dynamic model of perifused islets. Since the synthesis of Gln, NO and polyamines has been demonstrated to be involved in OKG effects (Vaubourdolle et al. 1990; Moinard et al. 2002) and may also be implicated in OKG-induced insulin secretion, specific inhibitors of the suggested pathways, namely $\mathrm{L}-\mathrm{N}^{\mathrm{G}}$-nitroarginine methyl ester (L-NAME), an effective inhibitor of NO synthase, methionine sulfoximine (MSO), a glutamine synthetase inhibitor, and difluoromethylornithine (DFMO), an inhibitor of polyamine synthesis, were used in order to evaluate their contribution.

\section{Materials and methods}

Animals

Seven- to eight-week-old non-fasted male Wistar rats (Charles River, St-Aubin-les-Elbeuf, France) weighing $250-300 \mathrm{~g}$ were used in all the experiments. They were housed under standard conditions and allowed free access to food (A04; UAR, Epinay-sur-Orge, France) and tap water until the time of islet isolation.

The study complied with general recommendations for animal care and handling. Three of the investigators (S.D., L.C. and G.R.) are officially authorised by the French Ministry of Agriculture and Forestry to perform experimental research on rats.

\section{Reagents}

Arg, Orn, $\alpha-\mathrm{KG}$, L-NAME and MSO were obtained from Sigma-Aldrich (St Louis, MO), DFMO was purchased from Calbiochem (San Diego, CA) and OKG was a generous gift from Chiesi S.A. (Courbevoie, France). Analytical grade reagents for the preparation of buffer solutions were obtained from Sigma Aldrich.

The basal Krebs-Ringer buffer (KRB) (pH 7.4) contained $118.5 \mathrm{mmol} \mathrm{NaCl} / 1,2.54 \mathrm{mmol} \mathrm{CaCl} 2 / 1,1.19 \mathrm{mmol}$ $\mathrm{KH}_{2} \mathrm{PO}_{4} / 1, \quad 4.74 \mathrm{mmol} \quad \mathrm{KCl} / \mathrm{l}, \quad 25 \mathrm{mmol} \quad \mathrm{NaHCO}_{3} / \mathrm{l}$, $1.19 \mathrm{mmol} \mathrm{MgSO}_{4} / \mathrm{l}$, bovine serum albumin $(5 \mathrm{mg} / \mathrm{ml})$, D-glucose (Glc, $2.8 \mathrm{mmol} / \mathrm{l}$ ) and $10 \mathrm{mmol} \mathrm{4-(2-hydroxy-}$ ethyl)piperazine-1-ethanesulfonic acid/l (Marie et al. 2000).

\section{Method of islet isolation}

After anaesthesia of the rat with sodium pentobarbital ( $40 \mathrm{mg} / \mathrm{kg}$ intraperitoneally) (Sanofi, Libourne, France) the pancreas was dissected according to a modified method of Lacy \& Kostianovsky (1967). Briefly, after clamping the common bile duct at a point close to the duodenum outlet, a retrograde injection of $10 \mathrm{ml}$ Hanks' solution (Sigma Aldrich) containing $2.5 \mathrm{mg}$ collagenase (Liberase ${ }^{\circledR}$; Boehringer Mannheim, Mannheim, Germany) was made into the duct. The pancreas was then dissected and incubated for $20 \mathrm{~min}$ at $37^{\circ} \mathrm{C}$.

After filtration of the crude preparation, the islets were washed twice with Hanks' solution and hand-picked under a dissecting microscope. About 400 islets were isolated from each animal. Only freshly isolated islets were used for perifusion or incubation experiments.

\section{Incubation system}

All the experiments were carried out in ninety-six-well filtration plates (Millipore, Molsheim, France) using five islets per well and eight wells per experimental condition. The islets were transferred to the plates immediately after isolation and washed three times with basal KRB directly in the filtration plates. The islets were incubated 
immediately with $200 \mu \mathrm{l}$ of the effectors in KRB for $90 \mathrm{~min}$ at $37^{\circ} \mathrm{C}$ under an atmosphere of $95 \% \mathrm{O}_{2}$ and $5 \%$ $\mathrm{CO}_{2}(\mathrm{v} / \mathrm{v})$. For each experiment, two control groups were always studied in parallel: one in basal KRB, to determine basal insulin secretion; one with $16.5 \mathrm{mmol} \mathrm{Glc/l}$ as a functional control eliciting maximal insulin secretion. In all the experiments, islets were incubated in parallel with $10 \mathrm{mmol}$ Arg/l, since the effect of this amino acid on insulin secretion is well known (Malaisse et al. 1989a,b) and can be considered as a functional reference for amino acid-induced insulin secretion. At the end of the incubation period, supernatant fractions were collected and stored at $-80^{\circ} \mathrm{C}$ until insulin determination.

For experiments with metabolic inhibitors, a $30 \mathrm{~min}$ preincubation period was used, islets being incubated in KRB with or without L-NAME $(5 \mathrm{mmol} / \mathrm{l})$, an inhibitor of $\mathrm{NO}$ synthase (Schmidt et al. 1992), MSO ( $5 \mathrm{mmol} / \mathrm{l})$, an inhibitor of Gln synthase (Minet et al. 1997), or DFMO (5 mmol/l), an inhibitor of ornithine decarboxylase (Blachier et al. 1989a). After this pre-incubation period, the medium was changed and the islets were further incubated in the same medium with each of the effectors, $16.5 \mathrm{mmol} \mathrm{Glc/l}$, $10 \mathrm{mmol} \mathrm{Arg} / \mathrm{l}$ and $1 \mathrm{mmol} \mathrm{OKG} / \mathrm{l}$, alone or in the presence of inhibitors.

\section{Perifusion system}

Four perifusion chambers (Swinnex 13; Millipore Corp., Bedford, MA) were run simultaneously, the islets (eighty islets per chamber) being placed on Whatman filters (mesh $0.45 \mu \mathrm{m}$; Whatman Ltd., Maidstone, Kent, UK). Immediately after isolation, the islets were transferred into the perifusion chambers and perifused with basal $\mathrm{KRB}$, equilibrated with $95 \% \mathrm{O}_{2}$ and $5 \% \mathrm{CO}_{2}(\mathrm{v} / \mathrm{v})$ by continuous bubbling; the flow rate was set at $1 \mathrm{ml} / \mathrm{min}$. After a 60 min wash-out period during which the perifusate was continuously discarded, the perifusion was carried out with basal KRB for 30 min (basal period) followed by a perifusion with a stimulating concentration of $16.5 \mathrm{mmol}$ Glc/l, OKG $(0.25,0.5$ and $1 \mathrm{mmol} / \mathrm{l})$, Orn $(2 \mathrm{mmol} / \mathrm{l})$ or $\alpha-\mathrm{KG}(1 \mathrm{mmol} / \mathrm{l})$ for a $30 \mathrm{~min}$ stimulated period. The perifusate was then switched back to basal KRB and perifusion was continued for $60 \mathrm{~min}$. Perifusate was collected in fractions of $5 \mathrm{ml}$ for the two basal KRB periods and $2 \mathrm{ml}$ for the stimulated period, and immediately stored at $-80^{\circ} \mathrm{C}$ until insulin determination.

\section{Analytical methods}

Insulin was determined by radioimmunoassay using the INSIK-5 Kit (Diasorin, Saluggia, Italy) and rat insulin (Linco, St Charles, MO) as standard.

\section{Calculations and statistics}

All data are presented as the mean values and standard errors of the mean of four to eleven experiments. Unless stated otherwise, insulin secretion during incubation is presented in $\mu \mathrm{U} /$ islet per $90 \mathrm{~min}$ and during perifusion in $\mu \mathrm{U} /$ islet per min. For the perifusion experiments, basal and stimulated insulin secretions were evaluated by the area under the curve of insulin secretion as a function of time calculated by the trapezoidal method during the basal period (i.e. between time 0 and time $30 \mathrm{~min}$ after the start of the perifusion) and during the stimulated period (i.e. between time $32 \mathrm{~min}$ and $62 \mathrm{~min}$ ). To compare the early and late phase insulin secretion in the perifusion experiments, the stimulated period was divided into two 15 min periods, and insulin secretion (area under the curve) was calculated separately. These data are presented as the ratio to the corresponding basal value of insulin secretion.

Statistical analysis was performed by ANOVA followed by a Fisher test (StatView; SAS Institutes Inc., Cary, NC, USA); $P<0.05$ was considered statistically significant.

\section{Results}

\section{Secretory response to ornithine $\alpha$-ketoglutarate: dose-response study}

To investigate the effects of $\mathrm{OKG}$ on insulin secretion, OKG concentrations ranging from 0.25 to $2.5 \mathrm{mmol} / \mathrm{l}$ were first screened using the incubation method. In this set of experiments ( $n$ 11), islets of Langerhans were incubated for $90 \mathrm{~min}$ in the presence of various OKG concentrations or Glc $(16.5 \mathrm{mmol} / \mathrm{l})$ or Arg $(10 \mathrm{mmol} / \mathrm{l})$. Results of insulin secretion were compared with basal conditions. These data are presented in Fig. 1.

At $16.5 \mathrm{mmol} / \mathrm{l}$, Glc exhibits its well-known stimulating effect on insulin secretion, which was increased nine-fold compared with basal concentration. Also, OKG significantly stimulated insulin release. Whereas the increase in insulin secretion was significant for all $\mathrm{OKG}$ concentrations $v$. basal secretion, insulin secretion induced by higher $\mathrm{OKG}$ concentrations $(1.0$ and $2.5 \mathrm{mmol} / \mathrm{l})$ were significantly increased $v$. lower OKG doses. A dose-effect relationship was demonstrated by a close linear relationship between OKG concentration and insulin secretion ( $r$ 0.98; $P=0.003)$. Arg $(10 \mathrm{mmol} / \mathrm{l})$ induced an insulin secretion comparable to that elicited by OKG $(2.5 \mathrm{mmol} / \mathrm{l})$.

\section{Kinetics of ornithine $\alpha$-ketoglutarate action}

The effect of OKG was further characterised by perifusion experiments using $\mathrm{OKG}$ at concentrations that can be achieved in vivo during OKG administration (Cynober et al. 1984b, 1990). Islets of Langerhans were thus perifused (six experiments) with $16.5 \mathrm{mmol} \mathrm{Glc/l}$ or increasing concentrations of OKG $(0.25,0.5$ and $1.0 \mathrm{mmol} / \mathrm{l})$. Results of insulin secretion during the stimulated period were compared with those observed during the basal period (Fig. 2 (a) and (b)). In the presence of $\mathrm{OKG}$, insulin secretion increased with OKG concentrations and showed a significant first initial peak at $32-34 \mathrm{~min}(P<0.05 v$. basal insulin secretion). The peak value tended to increase as a function of OKG concentration (0.95 (SEM 0.34), 1.19 (SEM 0.35 ) and 1.45 (SEM 0.50) $\mu \mathrm{U} /$ islet per min respectively, NS). The OKG-induced insulin secretion remained significantly elevated $(P<0.05 v$. basal $)$ throughout the stimulated period (Fig. 2 (a)).

Perifusion with $16.5 \mathrm{mmol}$ Glc/l resulted in a biphasic stimulation of insulin secretion with a first significant 

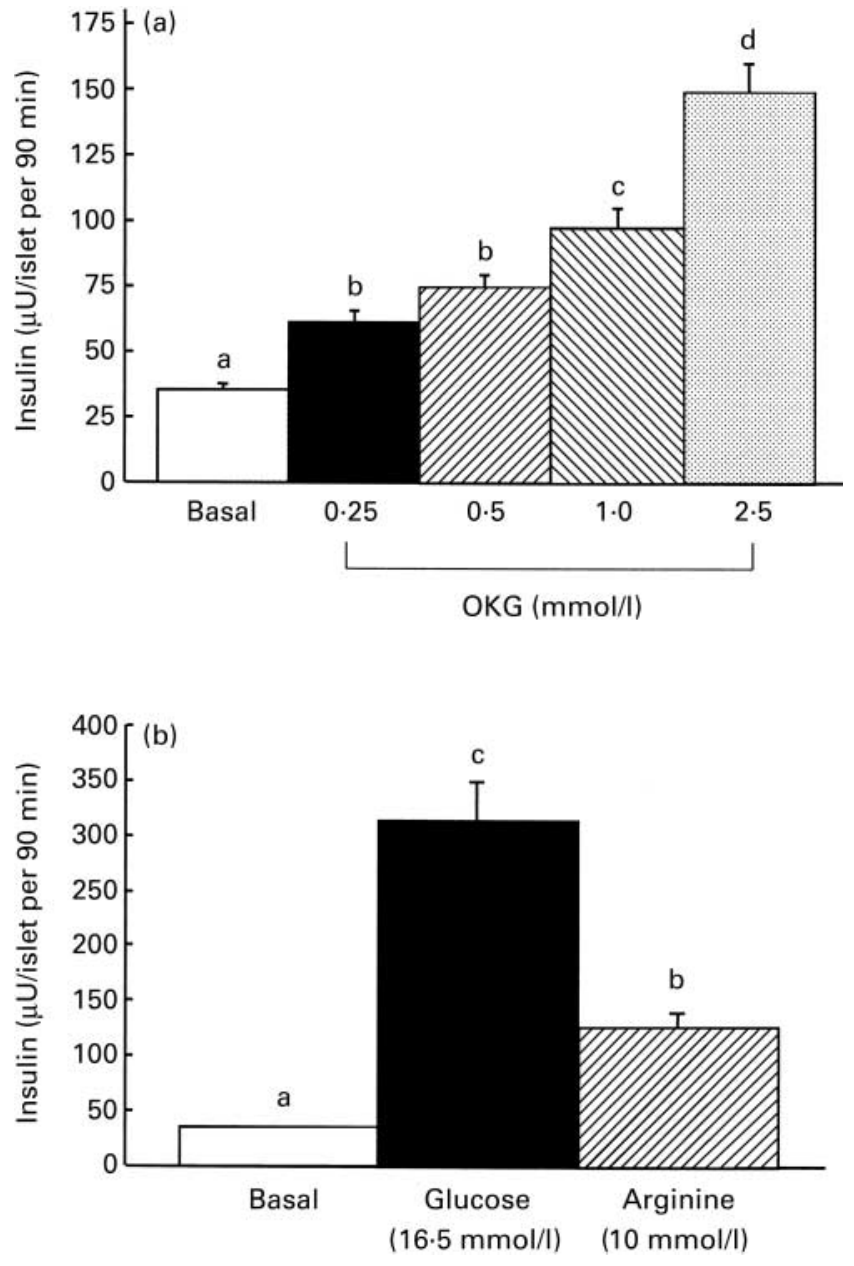

Fig. 1. Stimulating effects of ornithine $\alpha$-ketoglutarate (OKG) on insulin secretion by isolated rat Langerhans islets. Islets (five islets per well, eight wells per experimental condition) were incubated for $90 \mathrm{~min}$ at $37^{\circ} \mathrm{C}$ in basal Krebs-Ringer buffer: (a) alone or in the presence of OKG concentrations ranging from 0 to $2.5 \mathrm{mmol} / \mathrm{l}$; (b) alone or in the presence of $16.5 \mathrm{mmol}$ glucose $/ \mathrm{l}$ or $10 \mathrm{mmol}$ arginine/l. Mean values of insulin concentration in the media at the end of the incubation period are shown with the standard errors of the mean represented by vertical bars for eleven experiments per group. ${ }^{a, b, c, d}$ Groups with unlike superscript letters were significantly different $(P<0.05)$.

initial peak at $32 \mathrm{~min}$ and a significantly elevated late phase reaching a maximum at $52 \mathrm{~min}$ (Fig. 2 (b)).

To compare the early and late phases of insulin secretion, the stimulated period was divided into two periods of $15 \mathrm{~min}$. Perifusion with different OKG concentrations showed a significant stimulation in the early phase for the three OKG concentrations used (ratio to basal insulin secretion: $0.25 \mathrm{mmol} \mathrm{OKG} / \mathrm{l}, 1.79$ (SEM $0.31), \quad P<0.05 ; \quad 0.5 \mathrm{mmol}$ OKG/l, 2.14 (SEM 0.15), $P<0.05$; $1 \mathrm{mmol}$ OKG/1, 3.41 (SEM 0.68), $P<0.05$ ). On the other hand, only at the 0.5 and $1.0 \mathrm{mmol} / \mathrm{l}$ concentrations did OKG maintain a significant stimulation in the late phase until the end of stimulation (ratio to basal insulin secretion: $0.25 \mathrm{mmol}$ OKG/l, 1.41 (SEM 0.17), NS; $0.5 \mathrm{mmol} \quad \mathrm{OKG} / 1, \quad 1.79 \quad(\mathrm{SEM} \quad 0.13), \quad P<0.05 ; 1 \mathrm{mmol}$ OKG/1, 2.59 (SEM 0.34), $P<0 \cdot 05$ ).
Contribution of $\alpha$-ketoglutarate and ornithine to ornithine $\alpha$-ketoglutarate-induced insulin secretion

To evaluate the respective contribution of Orn and $\alpha-K G$, the two components of OKG, islets were perifused (six

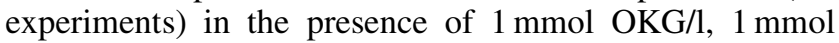
$\alpha-\mathrm{KG} / \mathrm{l}$ or $2 \mathrm{mmol}$ Orn/l, allowing for the presence of 2 mol Orn and $1 \mathrm{~mol} \alpha-\mathrm{KG}$ in $1 \mathrm{~mol} \mathrm{OKG}$ (six experiments).

As in previous experiments, OKG significantly stimulated insulin secretion. Both $\alpha-K G$ and Orn stimulated the early and late phase of insulin secretion significantly $(P<0.05)$ compared with basal secretion (Fig. 3 (a)), but the effects of both $\alpha-K G$ and Orn were significantly lower than that of OKG (Fig. 3 (b)).

\section{Effect of L-nitroarginine methyl ester on ornithine $\alpha$-ketoglutarate-induced insulin secretion}

To investigate the possible role of NO in the secretory response to $\mathrm{OKG}$, incubation experiments ( $n$ 6) were repeated with or without L-NAME, an NO synthase inhibitor. Results are presented in Fig. 4 (a) and (b).

While L-NAME alone at a concentration of $5 \mathrm{mmol} / \mathrm{l}$ tended to increase basal insulin secretion, it produced a significant reduction in both OKG $(1 \mathrm{mmol} / \mathrm{l})$ and $\mathrm{Arg}$ $(10 \mathrm{mmol} / \mathrm{l})$ effects on insulin secretion. On the other hand, in the presence of $16.5 \mathrm{mmol}$ Glc/l, L-NAME did not modify Glc-induced insulin secretion.

\section{Effects of methionine sulfoximine on ornithine $\alpha$-ketoglutarate-induced insulin secretion}

To examine the possible involvement of the Gln synthetase pathway in OKG effects, islets of Langerhans were incubated in the presence of $5 \mathrm{mmol} \mathrm{MSO} / \mathrm{l}$ (seven experiments per group). MSO did not affect either basal or Arg-stimulated insulin secretion. The results are presented in Fig. 5 (a) and (b). In the presence of MSO, OKG-induced insulin secretion was significantly reduced $(40 \% ; P<0.05)$.

\section{Effects of difluoromethylornithine on ornithine $\alpha$-ketoglutarate-induced insulin secretion}

To investigate the possible involvement of the polyamine pathway, incubation experiments were carried out in the presence of $5 \mathrm{mmol} \mathrm{DFMO} / \mathrm{l}$ (four experiments per group).

DFMO did not affect either basal insulin release or that induced by $16.5 \mathrm{mmol} \mathrm{Glc} / \mathrm{l}$ or Arg under these experimental conditions (data not shown). OKG-induced insulin secretion was not significantly modified by DFMO (basal secretion: 29 (SEM 7) $\mu \mathrm{U} /$ islet per $90 \mathrm{~min}$; OKG: 78 (SEM 22) $\mu \mathrm{U} /$ islet per $90 \mathrm{~min}$; OKG + DFMO: 72 (SEM 23) $\mu \mathrm{U} /$ islet per $90 \mathrm{~min} ; P<0.05 \mathrm{OKG}$ and $\mathrm{OKG}+\mathrm{DFMO} v$. basal secretion).

\section{Discussion}

Our aim was to investigate the insulinotropic effect of OKG and to study its possible metabolic pathways in isolated islets of Langerhans. OKG stimulates insulin secretion dose-dependently, inducing both the first and 
the second phase of insulin release. However, neither Orn nor $\alpha-K G$ alone, at concentrations equivalent to that of $\mathrm{OKG}$, reproduces the effects of OKG.

In both incubation and perifusion experiments, we observed a dose-dependent induction of insulin release by OKG, already significant at a concentration of $0.25 \mathrm{mmol} / \mathrm{l}$. This is in line with the OKG-induced increase in insulinaemia observed in vivo in healthy subjects (Cynober et al. 1984b, 1990). This effect was expected because numerous studies have pointed to the involvement of both $\alpha-\mathrm{KG}$ and Orn, the two components of OKG, in insulin secretion (Lenzen et al. 1986; Malaisse et al. 1989a). However, most of these findings were based on effector concentrations higher than those used in the present experiments. Experimental conditions such as basal Glc concentration may partly explain some of the differences between our results and those reported in the literature. For example, Blachier et al. (1989b) showed a marked increase in insulin release in incubated and perifused rat islets in the presence of $10 \mathrm{mmol}$ Orn/l and $5.6 \mathrm{mmol} \mathrm{Glc} / \mathrm{l}$, while other experiments failed to demonstrate any Orn effect below 3 to $5 \mathrm{mmol} / \mathrm{l}$. Our findings indicate that Orn alone or as its $\alpha-K G$ salt stimulates insulin secretion significantly in a range of concentrations (i.e. 0.5 to $1.0 \mathrm{mmol} / \mathrm{l}$ ) achieved during in vivo administration (Cynober, 1995), but neither $\alpha-\mathrm{KG}$ nor Orn by itself reproduces OKG-induced insulin secretion. Similar results were obtained in islets from pigs (data not shown) suggesting that the observed effects are not species-related. Orn and $\alpha-K G$ induced the first initial peak and the second phase of insulin secretion, insulin release during each of these two periods being approximately half of total release during the stimulated period.
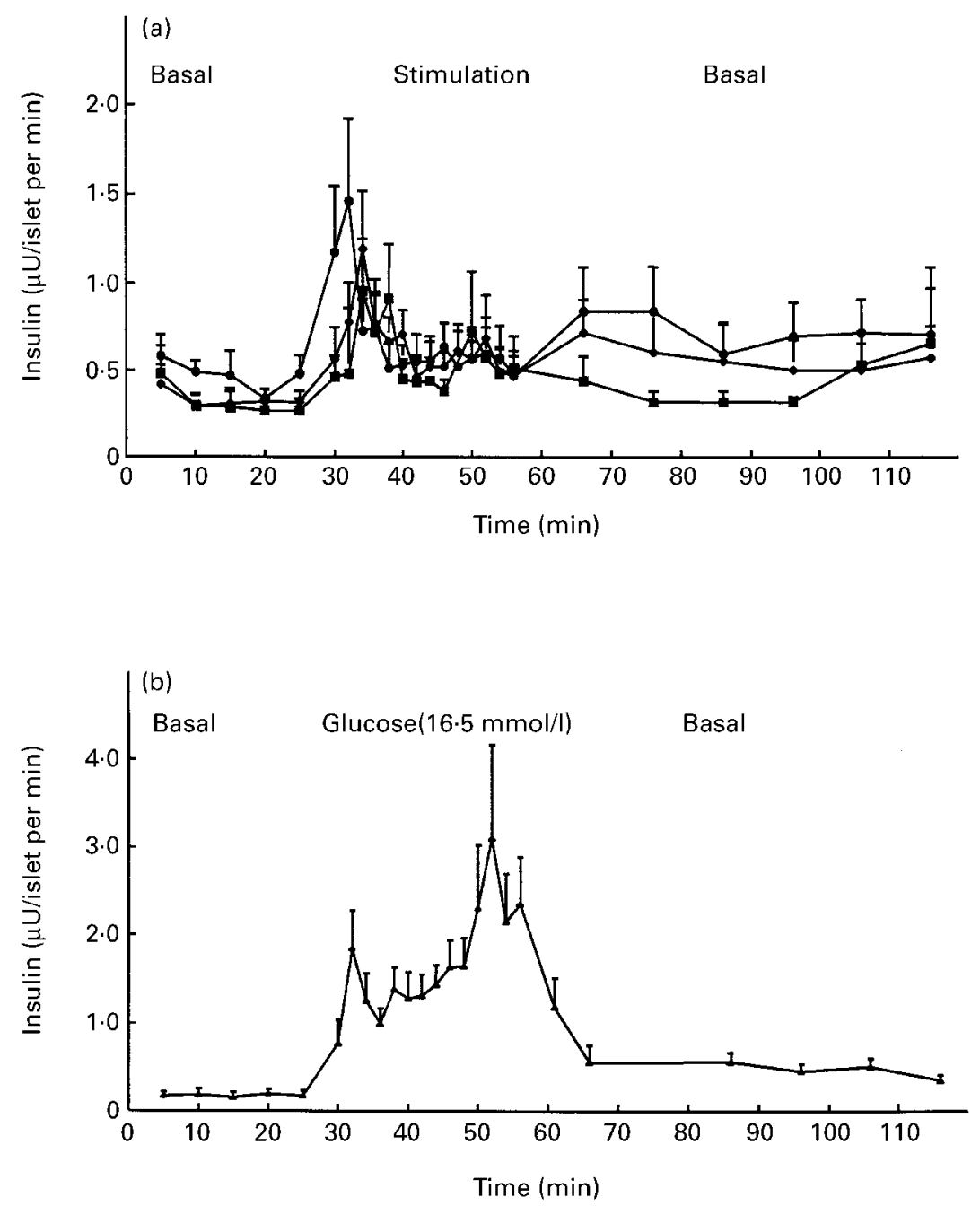

Fig. 2. Kinetics of ornithine $\alpha$-ketoglutarate (OKG) action on insulin secretion in perifused Langerhans islets. After a basal period in Krebs-Ringer buffer (30 min), islets (eighty islets per chamber and per experimental condition) were perifused for $30 \mathrm{~min}$ in the presence of either: (a) OKG at one of three different concentrations $((-\mathbf{-}-), 0.25$; $(--)$, 0.5; (-๑-), $1.0 \mathrm{mmol} / \mathrm{l})$; (b) $16.5 \mathrm{mmol}$ glucose $/ \mathrm{l}(-\boldsymbol{\Delta}-)$. Mean values of insulin secretion (six experiments per group) in the perifusion media during basal and stimulated perifusion periods are shown, with the standard errors of the mean represented by vertical bars. There were no statistical differences between groups during the basal and post stimulation periods. 
These results suggest that both compounds are involved in the OKG effect, and that the simultaneous action of $\alpha-K G$ and Orn is required for the insulinotropic effect of OKG. Since OKG completely dissociated in aqueous solution, the effect of simultaneous addition of $\alpha-K G$ (as its sodium salt) and Orn (as its hydrochloride salt) was not tested. However, Fig. 3 shows that $\alpha-K G$ and Orn by themselves account respectively for nearly 30 and $60 \%$ of OKG effects, suggesting that in these conditions the effects of $\alpha-K G$ and Orn are merely additive. Nevertheless, further experiments are needed to clarify this point. Moreover, as the insulin secretory properties of non-Glc secretagogue is largely influenced by Glc concentration, it would be interesting to evaluate the effects of Orn and $\alpha-K G$ in the presence of different Glc concentrations.

An $\alpha-K G-O r n$ interaction has been suggested to induce several anabolic effects of OKG by promoting Arg and Gln synthesis (Cynober et al. 1990; Le Boucher et al. 1997), based on a metabolic pathway common to Orn and $\alpha$ KG. When these two compounds are administered simultaneously, saturation of this common pathway favours the utilisation of $\alpha-\mathrm{KG}$ and Orn in other pathways, such as Arg, Gln or polyamine synthesis (Cynober, 1999), both potentially involved in insulin secretion (Malaisse et al. 1982; Welsh \& Sjöholm, 1988; Schmidt et al. 1992).

Our data, which confirm in vivo observations of OKGinduced insulin secretion in healthy subjects, led us to investigate the underlying mechanisms. Three different pathways of OKG metabolism may be involved: (i) the production of NO through the synthesis of Arg; (ii) the production of glutamate via transamination of both Orn and $\alpha$ $\mathrm{KG}$; (iii) the decarboxylation of Orn into polyamines.

The first of these pathways we studied was the induction of NO production by exogenous Orn, since some data suggest that $\mathrm{OKG}$ effects may be related to the generation of NO (Moinard et al. 2002). This effect was evaluated
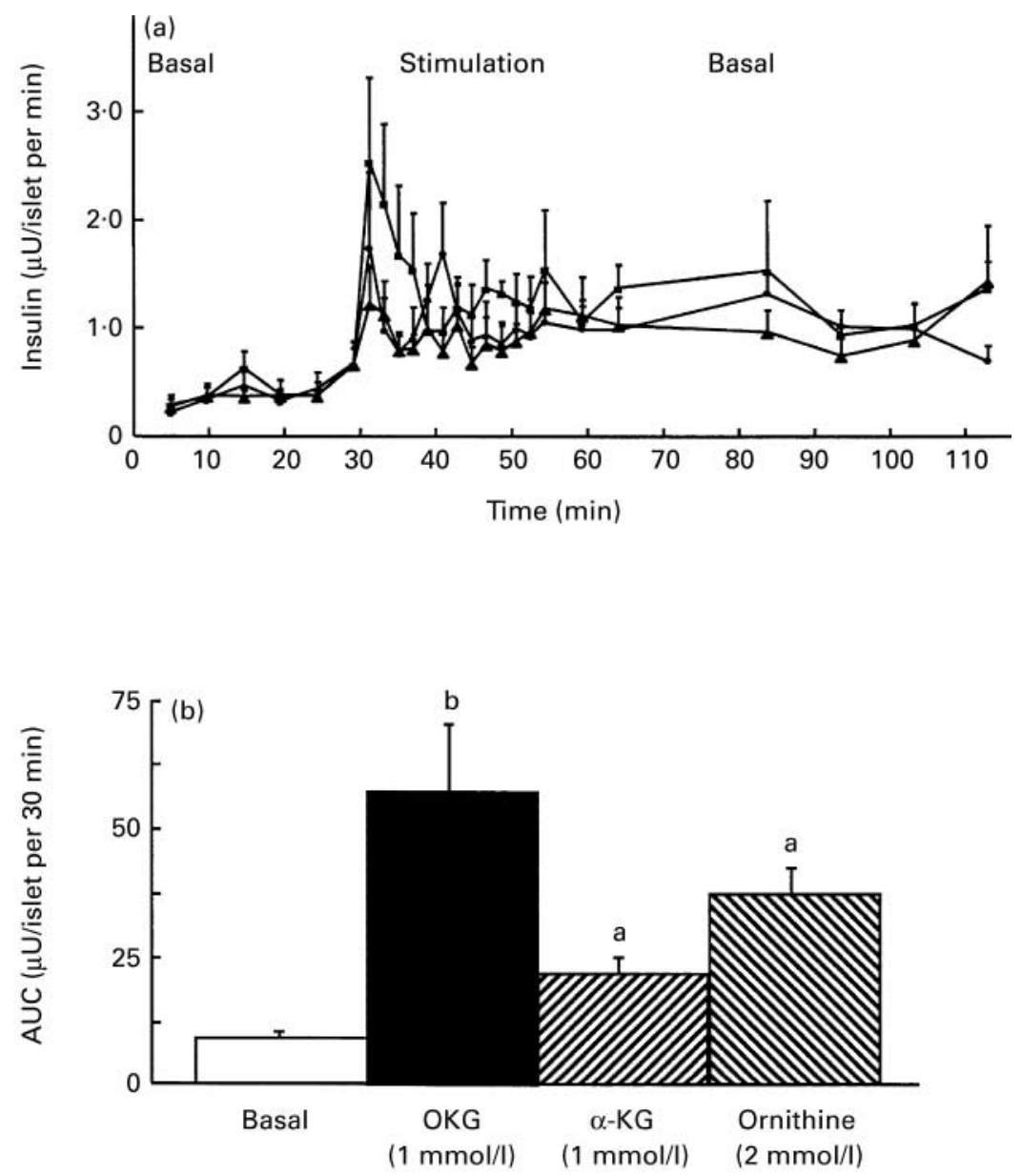

Fig. 3. Effects of ornithine $\alpha$-ketoglutarate (OKG) and equivalent concentration of $\alpha$ ketoglutarate $(\alpha-K G)$ and ornithine on insulin secretion by perifused rat Langerhans islets. After a basal period in Krebs-Ringer buffer $(30 \mathrm{~min})$, islets (eighty islets per chamber and per experimental condition) were perifused for $30 \mathrm{~min}$ with $1 \mathrm{mmol}$ OKG/I (-口-), $2 \mathrm{mmol}$ ornithine/l (-๑-) or $1 \mathrm{mmol} \alpha-\mathrm{KG} / \mathrm{l}(-\boldsymbol{\Delta}-)$. (a), Insulin secretion as a function of time; (b), area under the curve (AUC) of insulin production as a function of time during perifusion. Mean values of insulin secretion (six experiments per group) in the perifusion media during basal and stimulated perifusion periods are shown, with the standard errors of the mean represented by vertical bars. a,b Groups with unlike superscript letters were significantly different $(P<0.05)$. 
using L-NAME, an NO-synthase inhibitor. In incubation experiments, L-NAME ( $5 \mathrm{mmol} / \mathrm{l})$ significantly decreased OKG effects on insulin secretion, indicating an involvement of the NO synthase pathway and NO production in OKG-induced insulin secretion. These data suggest that conversion of Orn into Arg may be involved. However, Malaisse et al. (1989b) failed to demonstrate any significant synthesis of Arg from Orn in a tumoral cell line $(\mathrm{RINm} 5 \mathrm{~F})$ and in isolated islets. In addition, Sener et al. (1988) reported that rat islets are devoid of detectable ornithine transcarbamylase activity. On the other hand, recent studies suggest an implication of NO in Orn-induced insulin secretion, whereby sufficient amounts of Orn could be converted into Arg to enable NO production (Gross et al. 1997). Thus two hypotheses may be advanced. First, the NO synthase pathway may be quantitatively minor but metabolically significant. Second, Orn may have a sparing effect on Arg metabolism, leading to increased Arg avail- ability for NO production. Further work is required to clarify this issue.

The second mechanism we studied was the consequence of the interaction between $\alpha-\mathrm{KG}$ and Orn on glutamine metabolism (De Bandt \& Cynober, 1998). While the contribution of glutamate to the regulation of insulin secretion has been recently challenged (MacDonald \& Fahien, 2000), several studies emphasise the involvement of this amino acid in the regulation of insulin secretion (Malaisse, 1991; Maechler \& Wollheim, 1999; Rorsman \& Renström, 1999). On the other hand, as mentioned earlier, OKG exerts some of its metabolic effects via the synthesis of Gln, and could be a better precursor for Gln than Glc owing to transporter specificity and intracellular channelling (Cynober, 1999). We therefore studied insulin secretion in the presence of MSO, an inhibitor of Gln synthase. Whereas MSO was without effect on basal or Arg-stimulated insulin secretion, it produced a significant
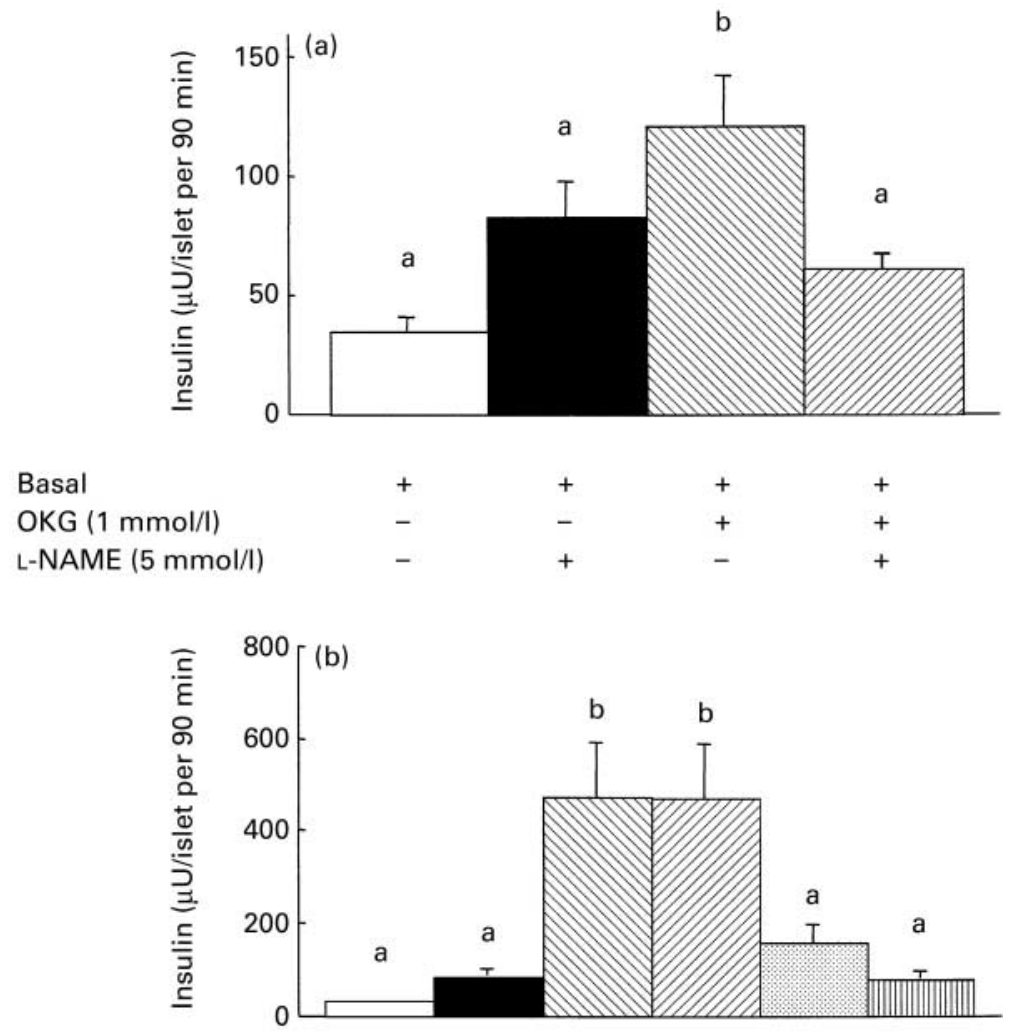

Basal

Glc (16.5 mmol/l)

$\operatorname{Arg}(10 \mathrm{mmol} / \mathrm{l})$

L-NAME ( $5 \mathrm{mmol} / \mathrm{l})$

$\begin{array}{llllll}+ & + & - & - & + & + \\ - & - & + & + & - & - \\ - & - & - & - & + & + \\ - & + & - & + & - & +\end{array}$

Fig. 4. Inhibition of ornithine $\alpha$-ketoglutarate (OKG)-induced insulin secretion by L-nitroarginine methyl ester (L-NAME) in incubated islets of Langerhans. Islets (five islets per well, eight wells per experimental condition) were incubated for $90 \mathrm{~min}$ at $37^{\circ} \mathrm{C}$ with or without $5 \mathrm{mmol}$ L-NAME// in basal Krebs-Ringer buffer: (a) alone or in the presence of $1 \mathrm{mmol} \mathrm{OKG} / \mathrm{l}$; (b) alone or in the presence of glucose (Glc, $16.5 \mathrm{mmol} / \mathrm{l})$ or arginine (Arg, $10 \mathrm{mmol} / \mathrm{l})$. Mean values of insulin concentration (six experiments per group) in the media at the end of the incubation period are shown, with the standard errors of the mean represented by vertical bars. ${ }^{a, b}$ Groups with unlike superscript letters were significantly different $(P<0.05)$. 


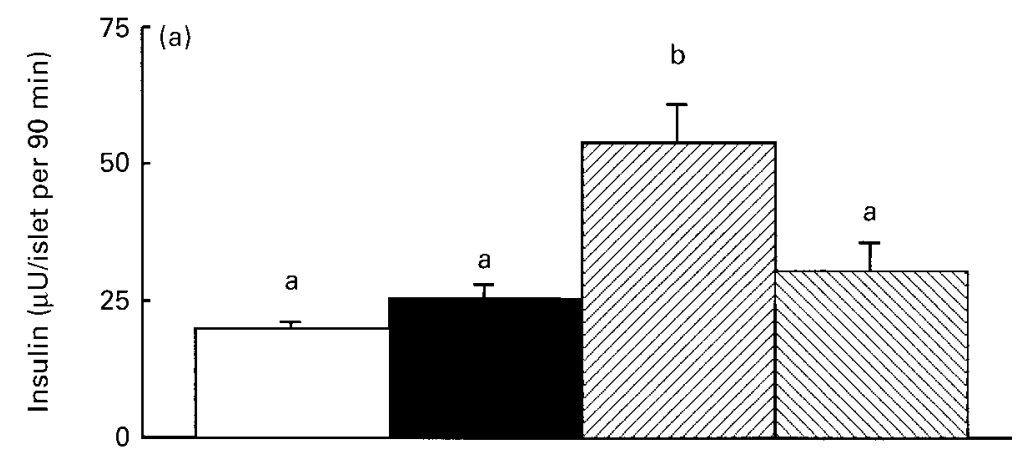

$\begin{array}{lllll}\text { Basal } & + & + & + & + \\ \text { OKG }(1 \mathrm{mmol} / \mathrm{l}) & - & - & + & + \\ \operatorname{MSO}(5 \mathrm{mmol} / \mathrm{l}) & - & + & - & +\end{array}$

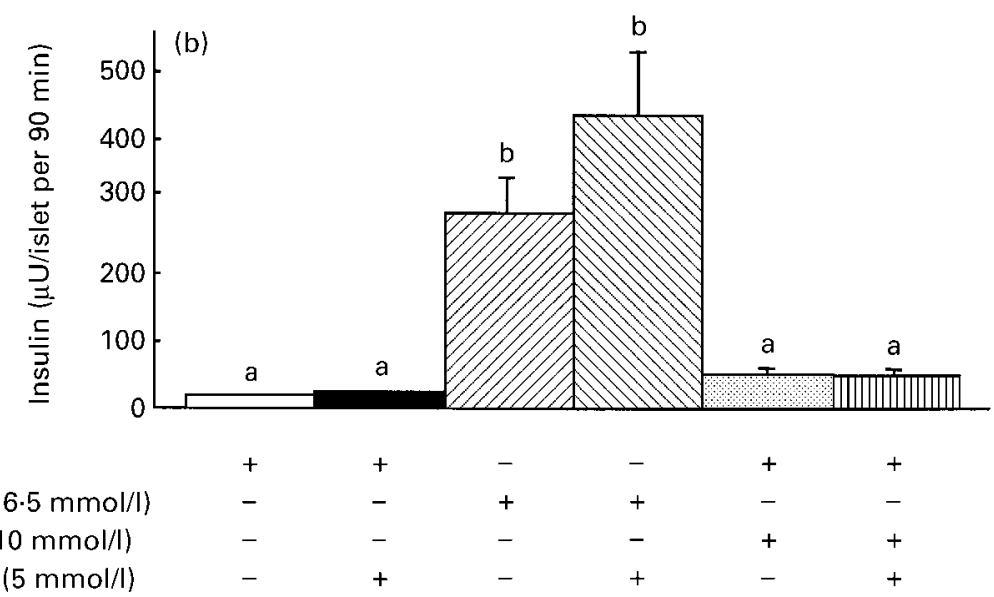

Fig. 5. Inhibition of ornithine $\alpha$-ketoglutarate (OKG)-induced $(1 \mathrm{mmol} / \mathrm{l})$ insulin secretion by methionine sulfoximine (MSO) in incubated islets of Langerhans. Islets (five islets per well, eight wells per experimental condition) were incubated for $90 \mathrm{~min}$ at $37^{\circ} \mathrm{C}$ with or without $5 \mathrm{mmol} \mathrm{MSO} / \mathrm{l}$ in basal Krebs-Ringer buffer: (a) alone or in the presence of $1 \mathrm{mmol} \mathrm{OKG} / \mathrm{l}$; (b) alone or in the presence of glucose (Glc, $16.5 \mathrm{mmol} / \mathrm{l}$ ) or arginine (Arg, $10 \mathrm{mmol} / \mathrm{l}$ ). Mean values of insulin concentration (six experiments per group) in the media at the end of the incubation period are shown, with the standard errors of the mean represented by vertical bars. ${ }^{a, b}$ Groups with unlike superscript letters were significantly different $(P<0.05)$.

reduction $(40 \%)$ in OKG-induced insulin release. This indicates that $\mathrm{OKG}$ acts partially on insulino-secretion via Gln synthesis. Whether this is related to intracellular channelling requiring a prior conversion of $\mathrm{OKG}$ into Gln or to some other mechanism related to glutamate availability remains to be determined.

Finally, the conversion of Orn into polyamines, a reaction catalysed by ornithine decarboxylase, was investigated. Polyamines seem to be involved in the regulation of Glc-sensitive insulin release, insulin biosynthesis and insulin mRNA content (Hoogarden et al. 1986; Welsh \& Sjöholm, 1988). Also, polyamines have been identified as major mediators of OKG-induced proliferation of fibroblasts in culture (Vaubourdolle et al. 1990). However, no effect of ornithine decarboxylase inhibition by DFMO on OKG-induced insulin release was observed in the present work. This suggests that the formation of polyamines does not play any role in the secretory response to OKG.
In conclusion, for the first time a direct effect of OKG on insulin secretion in isolated islets of Langerhans has been demonstrated. This effect seems to be due to the induction of both NO and Gln synthesis. Although the mechanisms by which the production of Gln contributes to insulin secretion remain to be fully elucidated, these findings contribute to a better understanding of the mechanisms of OKG action, and suggest that OKG administration may be useful in situations where insulin secretion is compromised.

\section{Acknowledgements}

This work was supported in part by a grant from Chiesi, SA, Courbevoie, France. C. S. was supported by a grant from 'Aide pour les jeunes diabétiques', Paris, France. 


\section{References}

Blachier F, Leclercq-Meyer V, Marchand J, Woussen-Colle MC, Mathias PC, Sener A \& Malaisse WJ (1989a) Stimulussecretion coupling of arginine-induced insulin release. Functional response of islets to L-arginine and L-ornithine. Biochimica et Biophysica Acta 1013, 144-151.

Blachier F, Mourtada A, Sener A \& Malaisse WJ (1989b) Stimulus-secretion coupling of arginine-induced insulin release. Uptake of metabolized and nonmetabolized cationic amino acids by pancreatic islets. Endocrinology 124, 134-141.

Cynober L (1995) Ornithine alpha-ketoglutarate. In Amino Acid Metabolism and Therapy in Health and Nutritional Disease, pp. 385-395 [L Cynober, editor]. Boca Raton, FL: CRC Press.

Cynober L (1999) The use of alpha-ketoglutarate salts in clinical nutrition and metabolic care. Current Opinion in Clinical Nutrition and Metabolic Care 2, 33-37.

Cynober L, Capeau J \& Ekindjian OG (1986) Cultured fibroblasts as a suitable model for studying insulin action on glucose uptake. Diabète et Metabolisme 12, 308-314.

Cynober L, Coudray-Lucas C, De Bandt JP, Guéchot J, Aussel C, Salvucci M \& Giboudeau J (1990) Action of ornithine alphaketoglutarate, ornithine hydrochloride, and calcium alpha-ketoglutarate on plasma amino acid and hormonal patterns in healthy subjects. Journal of the American College of Nutrition 9, 2-12.

Cynober L, Saizy R, Nguyen Dinh F, Lioret N \& Giboudeau J (1984a) Effect of enterally administered ornithine alpha-ketoglutarate on plasma and urinary amino acid levels after burn injury. Journal of Trauma 24, 590-596.

Cynober L, Vaubourdolle M, Dore A \& Giboudeau J (1984b) Kinetics and metabolic effects of orally administered ornithine alpha-ketoglutarate in healthy subjects fed with a standardized regimen. American Journal of Clinical Nutrition 39, 514-519.

De Bandt JP \& Cynober LA (1998) Amino acids with anabolic properties. Current Opinion in Clinical Nutrition and Metabolic Care 1, 263-272.

Gay G, Villaume C, Beaufrand MJ, Felber JP \& Debry G (1979) Effects of ornithine alphaketoglutarate on blood insulin, glucagon and amino acids in alcoholic cirrhosis. Biomedicine 30, $173-177$.

Gross R, Roye M, Manteghetti M, Broca C, Hillaire-Buys D, Masiello P \& Ribes G (1997) Mechanisms involved in the effect of nitric oxide synthase inhibition on L-arginine-induced insulin secretion. British Journal of Pharmacology 120, 495-501.

Hoogarden D, Nielsen J \& Larson L (1986) Localisation and biosynthesis of polyamines in insulin-producing cells. Biochemical Journal 238, 73-74.

Krassowski J, Rousselle J, Maeder E \& Felber JP (1981) The effect of ornithine-alpha-ketoglutarate on insulin and glucagon secretion in normal subjects. Acta Endocrinologica 98, $252-255$.

Lacy PE \& Kostianovsky M (1967) Method for the isolation of intact islets of Langerhans from the rat pancreas. Diabetes 16, 35-39.

Leander UF, Veterberg K \& Vinnars E (1985) Nitrogen sparing effect of Ornicetil in the immediate postoperative state. Clinical biochemistry and nitrogen balance. Clinical Nutrition $\mathbf{4}$, $43-51$.

Le Boucher J, Coudray-Lucas C, Lasnier E, Jardel A, Ekindjian OG \& Cynober LA (1997) Enteral administration of ornithine alpha-ketoglutarate or arginine alpha-ketoglutarate: a comparative study of their effects on glutamine pools in burn-injured rats. Critical Care Medicine 25, 293-298.
Le Boucher J, Farges MC, Minet R, Vasson MP \& Cynober L (1999) Modulation of immune response with ornithine $\alpha$-ketoglutarate in burn injury: an arginine or glutamine dependency? Nutrition 15, 773-777.

Lenzen S, Schmidt W, Rustenbeck I \& Panten U (1986) 2-ketoglut tarate generation in pancreatic B-cell mitochondria regulates insulin secretory action of amino acids and 2-keto acids. Bioscience Reports 6, 163-169.

MacDonald M \& Fahien L (2000) Glutamate is not a messenger in insulin secretion. Journal of Biological Chemistry 275, 34025-34027.

Maechler P \& Wollheim CB (1999) Mitochondrial glutamate acts as a messenger in glucose-induced insulin exocytosis. Nature 402, 685-689.

Malaisse W (1991) Metabolic factors influencing synthesis and secretion of pancreatic islet hormones. In The Endocrine Pancreas, pp. 73-92 [E Samols, editor]. New York: Raven Press Ltd.

Malaisse WJ, Blachier F, Mourtada A, Camara J, Albor A, Valverde I \& Sener A (1989a) Stimulus-secretion coupling of arginine-induced insulin release. Metabolism of L-arginine and L-ornithine in pancreatic islets. Biochimica et Biophysica Acta 1013, 133-143.

Malaisse WJ, Blachier F, Mourtada A, Camara J, Albor A, Valverde I \& Sener A (1989b) Stimulus-secretion coupling of arginine-induced insulin release: metabolism of L-arginine and L-ornithine in tumoral islet cells. Molecular and Cellular Endocrinology 67, 81-91.

Malaisse WJ, Sener A, Malaisse-Lagae F, Welsh M, Matthews DE, Bier DM \& Hellerstrom C (1982) The stimulus-secretion coupling of amino acid-induced insulin release. Metabolic response of pancreatic islets of L-glutamine and L-leucine. Journal of Biological Chemistry 257, 8731-8737.

Marie JC, Bailblé D, Gylfe E \& Portha B (2000) Defective glucose-dependent cytosolic $\mathrm{Ca} 2+$ handling in islets of GK and nSTZ rat models of type 2 Diabetes. Journal of Endocrinology 169, 169-176.

Minet R, Villie F, Marcollet M, Meynial-Denis D \& Cynober L (1997) Measurement of glutamine synthetase activity in rat muscle by a colorimetric assay. Clinica Chimica Acta $\mathbf{2 6 8}$, $121-132$.

Moinard C, Caldefie F, Walrand S, Tridon A, Chassagne J, Vasson MP \& Cynober L (2002) Effects of ornithine 2-oxoglutarate on neutrophils in stressed rats: evidence for the involvement of nitric oxide and polyamines. Clinical Science (London) 102, 287-295.

Rorsman P \& Renström E (1999) Cell biology: glutamate primes up the pump. Nature 402, 595-596.

Schmidt HH, Warner TD, Ishii K, Sheng H \& Murad F (1992) Insulin secretion from pancreatic B cells caused by L-arginine-derived nitrogen oxides. Science 255, 721-723.

Sener A, Blachier F \& Malaisse WJ (1988) Production of urea but absence of urea cycle in pancreatic islet cells. Medicine and Science Research 16, 483-484.

Vaubourdolle M, Cynober L, Lioret N, Coudray-Lucas C, Aussel C, Saizy R \& Giboudeau J (1987) Influence of enterally administered ornithine alpha-ketoglutarate on hormonal patterns in burn patients. Burns 13, 349-356.

Vaubourdolle M, Salvucci M, Coudray-Lucas C, Agneray J, Cynober L \& Ekindjian OG (1990) Action of ornithine alpha ketoglutarate on DNA synthesis by human fibroblasts. In Vitro Cellular and Developmental Biology 26, 187-192.

Welsh N \& Sjöholm A (1988) Polyamines and insulin production in isolated mouse pancreatic islets. Biochemical Journal 252, $701-707$. 